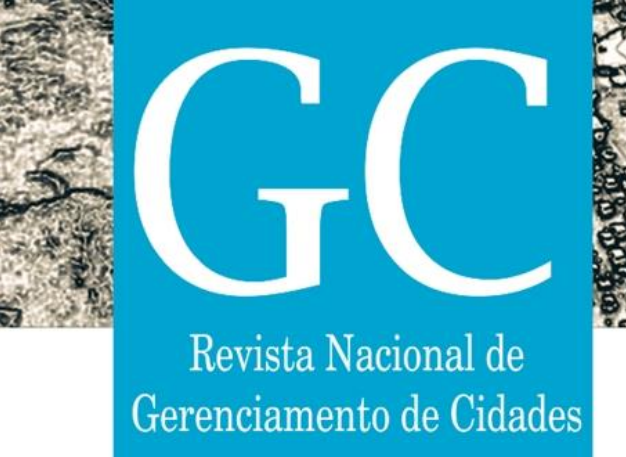

\title{
Parceria entre setor público e privado para gestão de parques urbanos e suas contribuições para a sustentabilidade
}

\author{
Public-private partnership for urban park management and their contributions to \\ sustainability
}

Asociación público-privada para la gestión del parque urbano y sus contribuciones a la sostenibilidad

Neiva Menezes Viana Mestre em Gestão Ambiental e Sustentabilidade, UNINOVE, Brasil.

neiva.menezes41@gmail.com

Ana Paula Branco do Nascimento Doutora em Ecologia Aplicada-Ambiente e Sociedade, Brasil. apbnasci@yahoo.com.br

Milena De Moura Regis Mestre em Gestão Ambiental e Sustentabilidade, UNINOVE, Brasil. mmregis@hotmail.com 


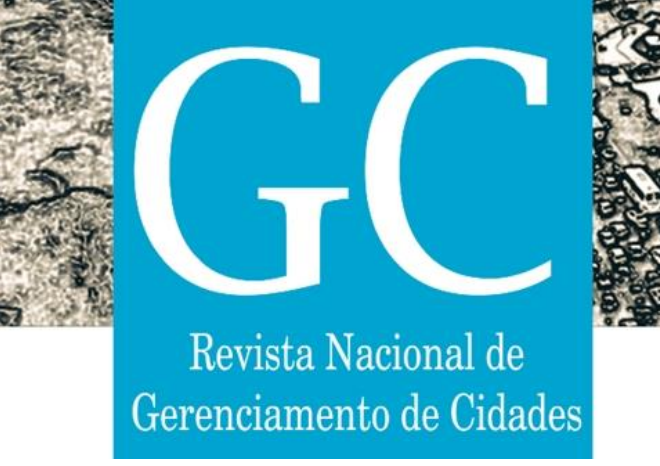

RESUMO

A prefeitura de São Paulo alcançou sua meta de atingir, e ultrapassar, o número de 100 parques municipais até o ano de 2012. A construção e a gestão destes espaços urbanos são essenciais para o desenvolvimento sustentável (ODS 11), entretanto tornou-se um desafio para a atual administração pública na cidade de São Paulo. Analisou-se a percepção de especialistas sobre Parcerias Público Privadas (PPP) para a gestão de Parques Urbanos. A coleta de dados foi entrevista estruturada com especialistas utilizando-se o método snowball. As entrevistas foram gravadas e transcritas e posteriormente analisadas no Software ATLAS. TI. A análise de conteúdo consistiu em uma pré-análise das falas dos especialistas, e em um segundo momento os trechos das falas foram categorizados. Na percepção dos especialistas, os benefícios das PPPs estão relacionados a uma melhoria na qualidade dos serviços prestados e redução dos custos públicos, uma vez que os riscos serão compartilhados. As PPPs têm benefícios no Brasil e também para a gestão de parques em São Paulo no modelo de concessão comum. Conclui-se que a parceria com o setor privado trará melhoria na qualidade dos serviços prestados no parque. O edital não contempla a proteção da biodiversidade e nem inclui um plano diretor prévio, tornando a parceria transparente. Sugere-se diálogo entre o governo e a sociedade, envolvendo o conselho gestor dos parques envolvidos para garantir que as metas do ODS 11 sejam cumpridas.

Palavras-chave: Áreas Verdes. Parques Urbanos. Cidades Sustentáveis.

\section{ABSTRACT}

The city of São Paulo reached its goal of reaching the number of 100 municipal parks, and overtake, by the year 2012. The management and maintenance of these spaces has become a challenge for public administration, where the solution is focused on a public and private partnership. The perception of specialists for the current scenario of a Public Private Partnership was analyzed, as well as the perception of these experts for the contributions of the PPPs to the management of Urban Parks. The data collection was a structured interview with experts using the snowball method. The interviews were recorded and transcribed and later analyzed in ATLAS Software. The content analysis consisted of a pre-analysis of the expert's speeches, and in a second moment the excerpts of the speech were categorized. In the experts' perception, the benefits of PPPs are related to an improvement in the quality of services provided and reduction of public costs, since risks will be shared. PPPs have benefits in Brazil and also for park management in São Paulo in the common concession model. It is concluded that the partnership with the private sector will improve the quality of the services provided in the park. The notice does not contemplate the protection of biodiversity and does not include a previous master plan, making the partnership transparent. It is suggested a dialogue between the government and society, involving the management council of the involved parks.

Keywords: Green Areas. Urban parks. Sustainable cities.

\section{RESUMEN}

La ciudad de São Paulo ha alcanzado su objetivo de llegar, y adelantar, a 100 parques municipales para el año 2012. La construcción y gestión de estos espacios urbanos son esenciales para el desarrollo sostenible (ODS 11), pero se ha convertido en un desafío para el actual. administración pública en la ciudad de São Paulo. Se analizó la percepción de expertos en Alianzas Público Privadas (PPP) para la gestión de Parques Urbanos. La recolección de datos fue entrevistas estructuradas con expertos utilizando el método de bola de nieve. Las entrevistas fueron grabadas y transcritas y luego analizadas en el software ATLAS. IT El análisis de contenido consistió en un preanálisis de los discursos de los expertos, y en un segundo momento se categorizaron los extractos de los discursos. Según los expertos, los beneficios de las APP están relacionados con una mejora en la calidad de los servicios prestados y una reducción en los costos públicos, ya que los riesgos serán compartidos. Las APP tienen beneficios en Brasil y también para la gestión de parques en São Paulo bajo el modelo de concesión común. Se concluye que la asociación con el sector privado traerá una mejora en la calidad de los servicios prestados en el parque. El aviso no aborda la protección de la biodiversidad ni incluye un plan maestro previo, lo que hace que la asociación sea transparente. Se sugiere un diálogo entre el gobierno y la sociedad, involucrando al consejo de administración del parque involucrado para asegurar que se cumplan los objetivos del ODS 11.

PALABRAS CLAVE: Áreas verdes. Parques urbanos. Ciudades sostenibles. 
Revista Nacional de

Gerenciamento de Cidades

\section{INTRODUÇÃO}

A Agenda 2030 que contempla os objetivos do desenvolvimento sustentável (ODS), afirma que muitas metas precisam ser cumpridas para um mundo mais sustentável (AGENDA 2030). Atualmente, a valorização e contato com a natureza tem se tornado importante para o ser humano, pois este tem demonstrado interesse numa reaproximação física. Neste sentido, espaços verdes, são espaços urbanos que trazem benefícios a população (SANTOS et al., 2019). Além disso, a conservação destes espaços é uma necessidade, e em grandes cidades, uma vez que contribuem para a qualidade de vida dos munícipes.

Os primeiros parques urbanos foram criados em paralelo a formação das cidades na Europa e também nos Estados Unidos (SILVA; PASQUALETO, 2013). Parques são espaços verdes que apresentam benefícios ecológicos e sociais. São áreas voltadas ao lazer, esporte, descanso e contato com a natureza, as quais devem ser utilizadas e conservadas pela população (DORIGO; LAMANO-FERREIRA, 2015). Dessa forma, estes espaços além de exercerem a função de atender as necessidades de lazer da população, também tem a função de proporcionar a conservação da natureza.

Em maio de 2017 a prefeitura do município de São Paulo publicou o edital de Procedimento de Manifestação de Interesse (PMI). O documento se referiu a concessão de 14 parques municipais. A partir desta publicação, a Prefeitura recebeu 18 estudos de modelagem operacional, jurídica, econômico-financeira e de engenharia e arquitetura. Esses estudos serviram para definir um modelo de concessão a ser aderido pela gestão pública. O modelo de concessão baseia-se na Lei № 16.703 de 4 de outubro de 2017- Disciplinas as Concessões e Permissões de Serviços. As obras e bens públicos serão executadas dentro do Plano Municipal de Desestatização (PMD). A lei incorpora mudanças na Lei № 16.211/2015, e a proposta foi Parceria Público Privada (PPP) para seis parques urbanos na cidade de São incluindo o Parque Ibirapuera Conservação.

São Paulo é uma cidade, resultado de crescimento rápido e desordenado, com poucas áreas verdes, em relação ao 12,176 milhões de habitantes (IBGE, 2018). A maior parte dos espaços verdes existentes na cidade são fragmentos de Mata Atlântica ou ambientes construídos, praças e parques, os quais não possui a maior parte da vegetação composta por espécies do Bioma. Para as áreas verdes proporcionarem bem-estar e melhorar a qualidade de vida dos munícipes (ODS 3), a cidade precisaria ter pelo menos $12 \mathrm{~m}^{2} /$ há, de acordo com o recomendado pela Organização Mundial de Saúde (OMS).

Várias ações têm sido desenvolvidas para melhorar a redução de espaços verdes causados pela urbanização. Como por exemplo, pode-se citar o programa "100 Parques para São Paulo". Essa proposta assumida pelo prefeito de São Paulo foi finalizada em 2012. Entretanto, muitos dos parques criados até esta data, não contam com áreas verdes que forneçam aos frequentadores benefícios como sombreamento, melhorias na qualidade do ar entre outros (SZEREMETA; ZANNIN, 2013). No total de 106 parques municipais da cidade, a maioria ainda 


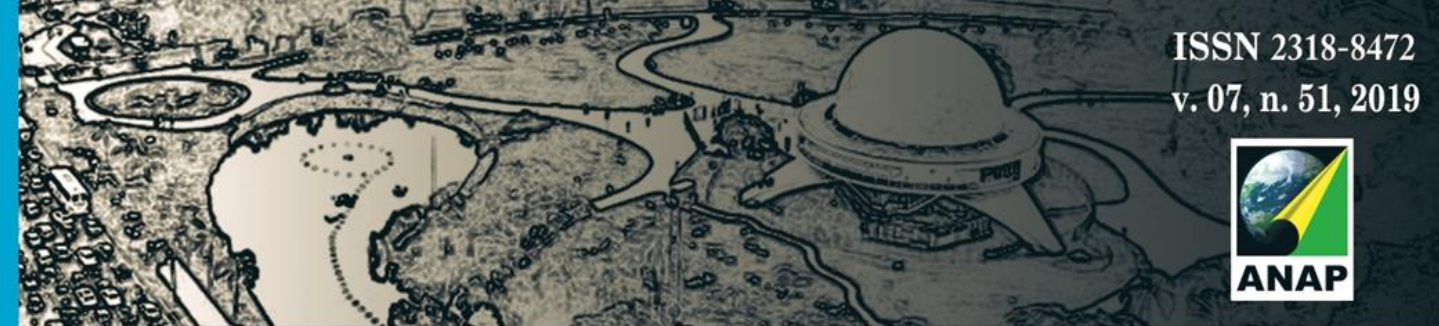

Revista Nacional de

Gerenciamento de Cidades

A partir das conversas com gestores públicos, verificou-se que muitos termos eram utilizados como sinônimos, como termo de cooperação, convênios e parcerias. Entretanto, no site da prefeitura (PMSP, 2017), é citado contratos, convênios e parcerias, cada um com um conceito distinto. Contratos referem-se a instrumentos administrativos que estabelecem os direitos e obrigações entre o poder público e particulares; convênio está relacionado a um acordo firmado entre uma entidade da administração pública municipal e uma entidade pública municipal, estadual, federal ou distrital da administração direta ou indireta ou organizações particulares sem fins lucrativos, para buscar objetivos de interesse comum entre as partes. $\mathrm{E}$ por último o termo de Parceria é o instrumento jurídico para transferência de recursos para organizações sociais de interesse público.

A técnica de pesquisa escolhida para este estudo foi entrevista. Estas, foram realizadas por pauta Vergara (2009), em que consistiu em a autora explorar vários pontos em profundidade com os entrevistados, combinando uma entrevista exploratória e descritiva. As entrevistas foram padronizadas, sendo seguido um roteiro previamente estabelecido e com pessoas indicadas, no estilo snowball (BIERMACKIE; WALDORF, 1981). Esta técnica garantiu que os entrevistados eram especialistas no tema parceria público privada, e descreveram suas percepções sobre a PPP para gestão de parques (Figura 1).

Figura 1. Especialistas em Parceria Público Privada, atuantes no setor público, privado ou academia, entrevistados neste trabalho.

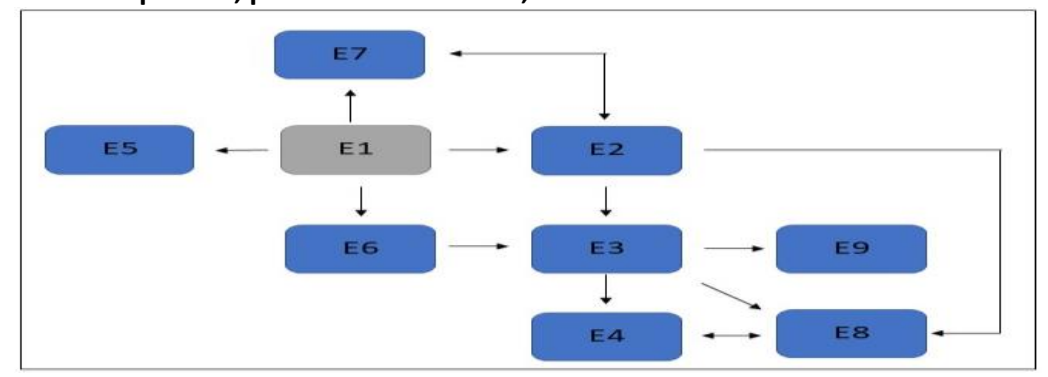

Fonte: Elaborado pelas autoras.

As entrevistas foram agendadas de acordo com a disponibilidade dos especialistas. A partir do primeiro informante (E1), criou-se uma rede de indicações, em que cada entrevistado indicou um ou dois especialistas para complementar as informações do estudo. As setas na figura 1, demonstram as indicações, em que o E8 (entrevistado 8), foi indicado por três outros especialistas. E a partir do E9 não houveram outras indicações. A pesquisa foi direcionada para especialistas em PPP, sendo três especialistas do setor público, três especialistas do setor privado e por último três especialistas atuantes na academia.

A pesquisa investigou a percepção de especialistas para a gestão de PPPs em Parque Urbanos em São Paulo (Quadro 1). As perguntas aos especialistas sobre PPP foram direcionadas para o caso de parques municipais. Todas perguntas foram gravadas e transcritas na íntegra. Cabe ressaltar que a pesquisa documental e conversas informais auxiliaram muito na elaboração do roteiro. 


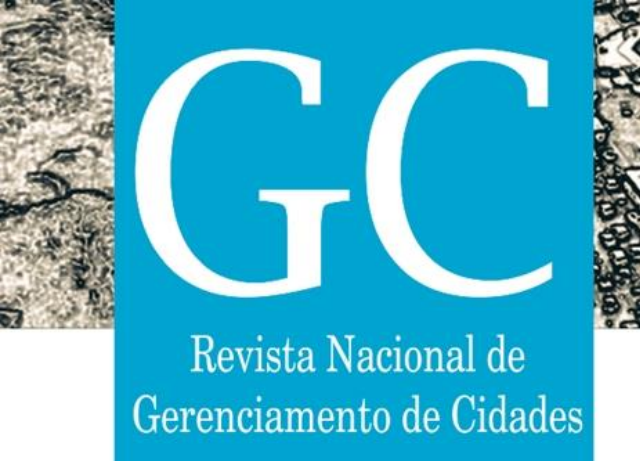

determinarão a consistência e a relevância dos resultados. Desta forma, nesta parte da pesquisa houve dedicação e leitura, muitas vezes as falas e categorias foram revisitadas para garantir resultados fidedignos e consistentes.

O uso de softwares específicos para análises de textos tem sido mais presente na literatura acadêmica. Para este estudo o software escolhido para a organização e análise de conteúdo foi o Atlas/TI (FRIESE, 2014). Este foi desenvolvido no contexto de um projeto multidisciplinar (1989-1992) na universidade de Berlim. Este software foi desenvolvido para dar flexibilidade ao pesquisador, em que cada um pode desenvolver seu processo de análise assim como técnicas mais apropriadas a sua análise.

\section{RESULTADOS}

As implementações das PPPs, compreende uma necessidade no Brasil, pois é percebível uma escassez de recursos públicos, o que causa uma certa carência na infraestrutura do país. No entanto, as falas dos especialistas demonstram que a percepção deles sobre a aplicação da PPP para parques ainda precisa ser construída, pois envolve um contrato, e um plano diretor para cada parque antes da parceria. São questões que viabilizam uma parceria entre o setor público e o privado. No Brasil ainda é um instrumento novo (E1), que vem se desenvolvendo para possibilitar a capacidade de o Estado atender as demandas de políticas, econômicas e sociais Silva et al. (2013). De acordo com o E1 é uma novidade na gestão (Quadro 2). 


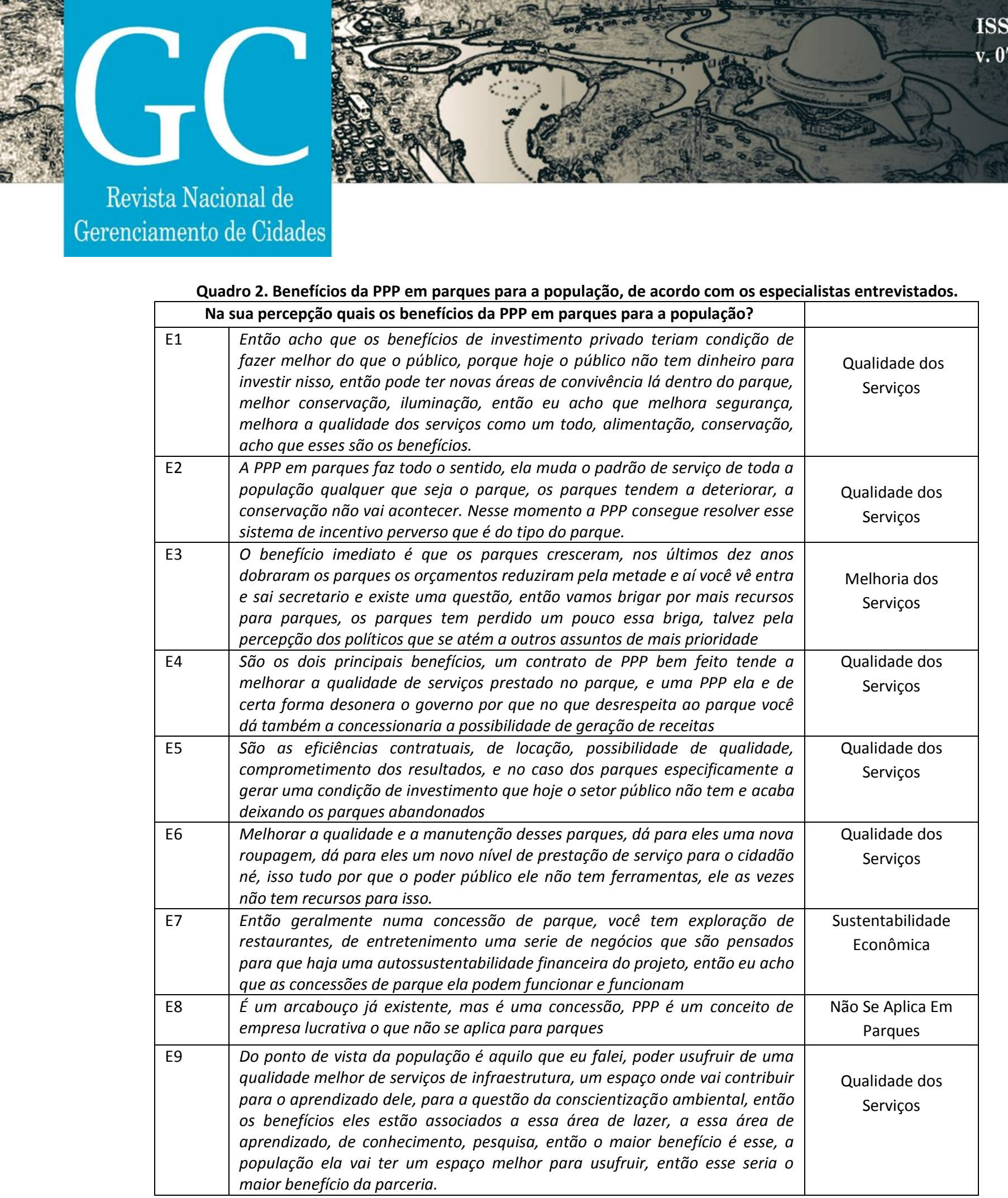

Fonte: Elaborado pela autora.

O quadro a seguir contém trechos das respostas dos especialistas sobre a percepção de cada um em relação aos benefícios da Parceria Público Privada em parques para a população. Para o especialista (E1), ele acredita que o setor privado tem mais possibilidades de investimento do que o público. Ele considera que os parques têm áreas de convivência e requer melhor conservação, iluminação, segurança, melhorando a qualidade dos serviços prestados para seus frequentadores. 


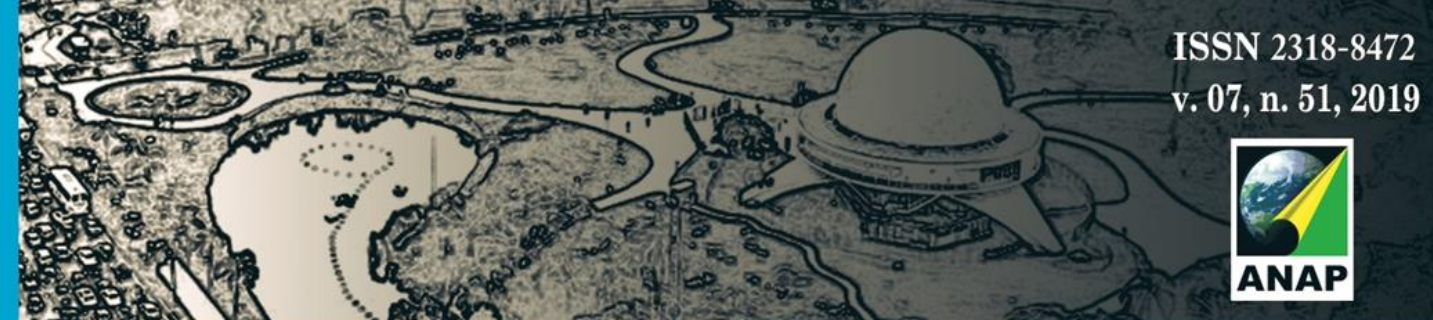

Revista Nacional de

Gerenciamento de Cidades

Os especialistas (E2 e E3) reforçam que PPP para parques fazem muito sentido, devido ter aumentado o número de parques nos últimos dez anos, e o orçamento público ter diminuído e os parques estarem expostos a deterioração. Outra questão é a troca de secretários, que atrapalha nos recursos para cuidar dos parques. Neste contexto político, os parques perdem a prioridade. Outros benefícios apontados pelos especialistas são os contratos bem feitos, porque vai melhorar os serviços prestados para a população. No contrato de PPP o governo é desonerado, pois no que diz respeito aos parques a concessionária tem a possibilidade de gerar receitas (E4 e E5).

Para os especialistas E6 e E7, a PPP para parques vai melhorar a manutenção, pois o poder público não dispõe de recursos para os cuidados dos parques, pois a concessionária ela vai poder empreender em negócios de autossustentabilidade para os parques, com isso vai melhorar os serviços para os frequentadores. Para o especialista E8, a PPP não se aplica a parques. Na fala do E9, os frequentadores terão vantagens podendo usufruir de um melhor espaço que vai contribuir para a conscientização ambiental e aprendizado.

Quando se refere a concessão de serviços é indispensável definir os procedimentos para manter o equilíbrio entre o valor que vai ser pago e os encargos do concessionário, ou seja, esses valores serão pagos via tarifas que serão cobradas dos usuários. Portanto, a viabilização econômica do empreendimento ou serviços é uma condição fundamental para atração dos investimentos feitos pela iniciativa privada (BANDEIRA DE MELLO, 2004; DI PIETRO, 2005).

Na percepção dos especialistas o setor privado está mais bem equipado e fornece serviços de forma mais eficiente do que o setor público. As PPPs são vistas como uma forma de os governos aproveitarem o financiamento e o conhecimento técnico do setor privado para fornecer serviços de qualidade (FORRER et al., 2010). No entanto, todos os atores envolvidos (Estado, concessionária, usuário). Possuem o mesmo objetivo, que é a boa qualidade do serviço prestado. Desta forma, se o empreendimento atender aos padrões de qualidade, o lucro se torna legal para a concessionária, porém, inviabiliza a busca pela vantagem econômica por parte da gestão pública (SUZIGAN et al., 2007). A origem das colaborações públicoprivadas está presa na insuficiência financeira enfrentadas entidades pelo governo. Por este motivo surgiu as PPPs para parques sem fins lucrativos. Esta parceria para parques é justamente atribuída as dificuldades econômicas por parte do setor público. Outrossim, o subsídio para manutenção de parques cada vez mais sofre ameaça porque o governo prioriza outros serviços, como segurança pública, saúde e desenvolvimento urbano (JOASSARTMARCELLI, 2010).

A implementação das PPPs para o provimento e financiamento de serviços, é um modelo que deve ser visto como uma possibilidade para fornecer vantagens socioeconômicas (value for many) e um prestador de serviços de qualidade. O público é essencial para implementação e adequação do modelo. Isso quer dizer que as PPPs alcancem sua influência não só nas gestões público e privadas, mas também que o público seja envolvido nesse processo (GUIMARÃES, 2012). 
Quadro 3. Percepção de especialistas sobre os benefícios das PPPs para a Biodiversidade em parques urbanos.

\begin{tabular}{|c|c|c|}
\hline \multicolumn{2}{|r|}{ Na sua percepção quais os benefícios da PPP para a Biodiversidade? } & \multirow[b]{2}{*}{ Conscientizar } \\
\hline E1 & $\begin{array}{l}\text { Eu sugiro que isso seja um tema a ser abordado nos editais e nos contratos, mas } \\
\text { confesso que esse assunto eu nunca li sobre, nos projetos dos parques. Mas } \\
\text { acho que é fundamental que sejam escritas as regras para promover essa } \\
\text { proteção, inclusive poderia quem ficar com a concessão do lbirapuera, } \\
\text { promover cursos com escolas para a conscientização das pessoas sobre a } \\
\text { importância de se ter os parques. }\end{array}$ & \\
\hline E2 & $\begin{array}{l}\text { Parque traz biodiversidade num contexto difuso para o benefício privado, pode } \\
\text { até aproveitar benefício privado, mas o benefício social do equipamento ele é } \\
\text { difuso, nós temos que [inaudivel] para ver se a gente consegue pagar pelo } \\
\text { serviço de uma forma transparente e clara, estável. }\end{array}$ & Desafio \\
\hline E3 & $\begin{array}{l}\text { Acho que é um maior desafio da administração pública, seja para cuidar de } \\
\text { parques, seja para cuidar de outros equipamentos, seja para pensar na } \\
\text { conservação ou uso público do parque acho que está dentro da mesma } \\
\text { dificuldade referente ao poder público. }\end{array}$ & Desafio \\
\hline E4 & $\begin{array}{l}\text { É importante dizer que o contrato de PPP num parque ele tem um caderno de } \\
\text { encabulo que uma lista de obrigações que a concessionaria tem que prestar, } \\
\text { incluindo obviamente por exemplo cuidado a fauna e a flora em grande nivel de } \\
\text { detalhe }\end{array}$ & $\begin{array}{l}\text { Indicador de } \\
\text { desempenho }\end{array}$ \\
\hline E5 & $\begin{array}{l}\text { Isso pode ser convertido em indicadores de desempenho, e quem define esse } \\
\text { indicador de desempenho é o governo, então eu acho que a PPP pode sim ser } \\
\text { um instrumento que ajuda a biodiversidade }\end{array}$ & $\begin{array}{l}\text { Indicador de } \\
\text { desempenho }\end{array}$ \\
\hline E6 & $\begin{array}{l}\text { Você tem condições de criar obrigações especifica para aquele concessionário, } \\
\text { para aquele parceiro privado de manter a biodiversidade a preservação da flora } \\
\text { né, os ativos ambientais que estiverem naquele parque então acho que é } \\
\text { benéfico. }\end{array}$ & $\begin{array}{l}\text { Indicador de } \\
\text { desempenho }\end{array}$ \\
\hline E7 & $\begin{array}{l}\text { Eu acho que no caso de gestão de parques por via de PPP há uma série de } \\
\text { regras uma série de condiçães que serão previamente estabelecidas no contrato } \\
\text { e devem orientar ali a prestação de serviços a forma de gestão, de atendimento } \\
\text { ao usuário, então a biodiversidade tem um valor a ser pesado pela gestão de } \\
\text { parques, seja uma gestão estatal, seja uma gestão privada, então não acho que } \\
\text { tenha uma relação direta das PPPs na proteção da biodiversidade. }\end{array}$ & $\begin{array}{l}\text { Indicador de } \\
\text { desempenho }\end{array}$ \\
\hline E8 & $\begin{array}{l}\text { Eu não concordo que parques urbanos seja a proteção da biodiversidade, acho } \\
\text { que é o parque é uma cidade de meio ambiente para o homem e não para a } \\
\text { biodiversidade, a biodiversidade tem que está no campo, você tem uma } \\
\text { contradição, você tem um meio ambiente urbano e no meio tem um parque } \\
\text { nele, para dar aquele contraste, mas não concordo que seja a função desse } \\
\text { espaço manter a biodiversidade porque não é um local adequado para isso. }\end{array}$ & Nenhum \\
\hline E9 & $\begin{array}{l}\text { O benefício seria o estado poder focar mais tempo e nas áreas de conservação e } \\
\text { proteção, que é uma especialidade do estado.O privado ele também pode fazer } \\
\text { atividades nessa área, mas o estado tem uma maior vocação para isso, mais } \\
\text { tempo de atuação nessa área, então o benefício para proteção seria a } \\
\text { decorrência de maior dedicação para as ocorrências de proteção, então isso } \\
\text { melhora a conservação dos parques e a proteção da biodiversidade. }\end{array}$ & Nenhum \\
\hline
\end{tabular}

Fonte: Elaborado pela autora.

Segundo Hossne et al. (2010) grande parte da Biosfera está se perdendo, essas perdas se dão pelas atividades do homem, que contribui para a destruição dos habitats de animais e plantas. A biodiversidade é um patrimônio da biosfera, devido a sua limitação tem surgido novos conflitos, que envolve a negociação da divisão e apropriação dos recursos naturais.

O serviço e as características dos parques urbanos, se diferem conforme a gestão ambiental e o crescimento das cidades. Alguns parques, com isso, são planejados com o intuito de atender 


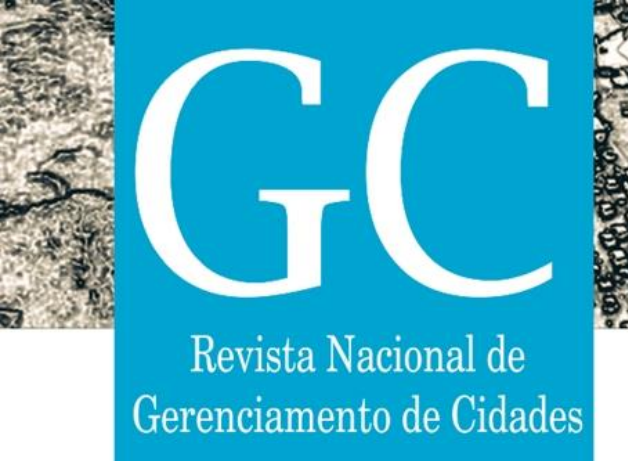

o maior número de pessoas, e outros parques estão estruturados para a conservação ambiental. Ambos, tem a mesma finalidade, de colaborar com a qualidade de vida da população que vivem na área urbana (CARDOSO et al., 2015).

No quadro 4, verifica-se trechos das falas dos especialistas sobre os desafios das PPPs para parques. Na fala do especialista E1 um dos principais desafios é o equilíbrio dos interesses públicos e privados e outro seria que todos os parques fossem contemplados e não somente $o$ Ibirapuera. Para o especialista E2 a falta de informação por parte do governo para com a população, pois se acredita que uma PPP seria uma privatização, ou seja, a venda de um parque para uma empresa privada. Na visão do E3 as Leis de PPPs precisam ser bem pensadas, pois elas se aplicam apenas para projetos acima de vinte milhões, e dá um exemplo de uma praça em Buenos Aires que o valor lá talvez precise de apenas um milhão. Para ele o projeto de PPP precisa ser pensando também para projetos abaixo do valor estipulado no contrato. Para o Entrevistado E4 ele diz que esse tipo de contrato por ser inédito no Brasil, traz uma série de dúvidas, pois no Brasil não existe nenhum contrato de PPP para parques urbanos. 


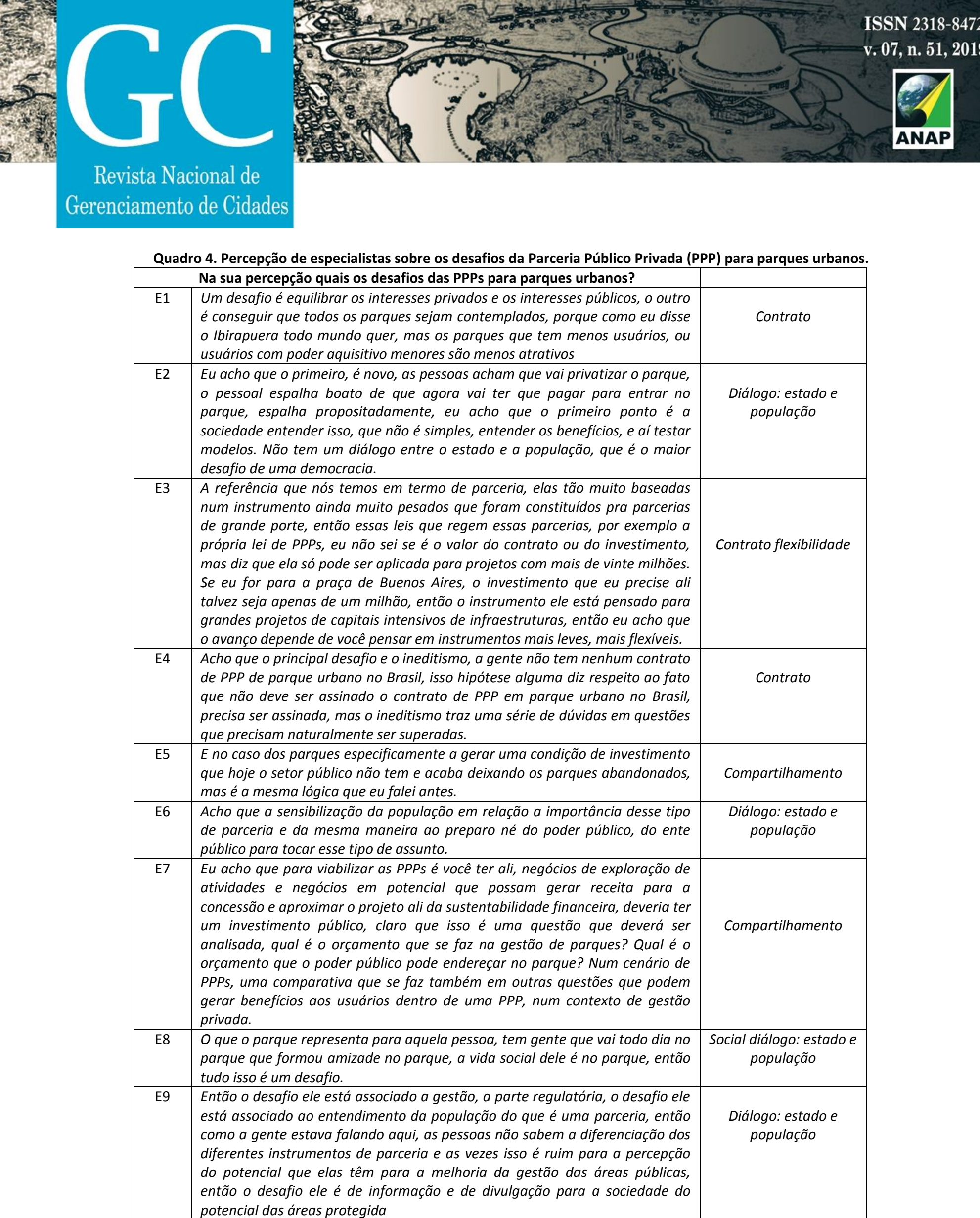

Fonte: Elaborado pelas autoras. 


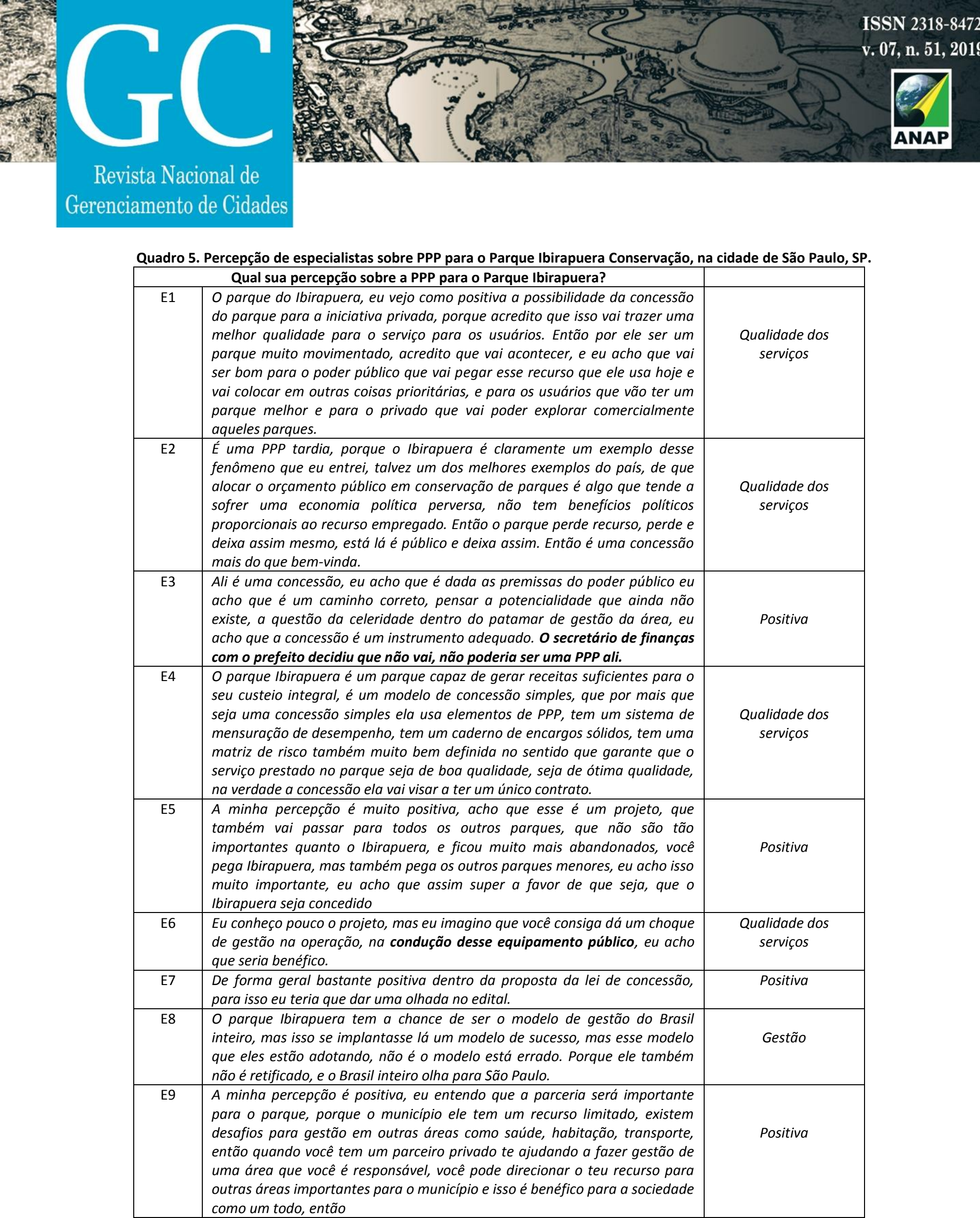

Quadro 5. Percepção de especialistas sobre PPP para o Parque Ibirapuera Conservação, na cidade de São Paulo, SP.

Fonte: Elaborado pela autora. 
